\section{ECCOMAS}

\author{
Proceedia
}

COMPDYN 2021

$8^{\text {th }}$ ECCOMAS Thematic Conference on Computational Methods in Structural Dynamics and Earthquake Engineering M. Papadrakakis, M. Fragiadakis (eds.) Streamed from Athens, Greece, 28 - 30 June 2021

\title{
SOIL-CAISSON-BRIDGE PIER-DECK DYNAMIC INTERACTION UNDER STRONG EARTHQUAKES: THE INFLUENCE OF PRIMARY AND SECONDARY SOIL NONLINEARITIES
}

\author{
D. Gaudio ${ }^{1}$ and S. Rampello ${ }^{1}$ \\ ${ }^{1}$ Sapienza University of Rome \\ via Eudossiana 18, 00184, Rome, Italy \\ e-mail: domenico.gaudio@uniromal.it \\ e-mail: sebastiano.rampello@uniroma1.it
}

\begin{abstract}
In the last few years, the ever-increasing computing power of personal computers has allowed to explore beyond the assumption of linear viscous-elastic behaviour usually made for foundation soils, even when subjected to strong seismic excitations. In this context, Gaudio and Rampello [1] performed a parametric study focusing on the seismic performance of massive caisson foundations supporting bridge piers subjected to strong one-directional earthquakes, capable of triggering the nonlinear and inelastic soil behaviour. 3D dynamic Finite Element (FE) analyses were performed twice in the time domain, once assuming the soil to behave as an elastic-plastic and once as a linear viscous-elastic medium: through the comparison of results, the observed reduction of inertial forces transmitted to the superstructure was mainly attributed to the energy dissipation occurring in the foundation soils, due to the attainment of their inelastic behaviour. These nonlinearities can be classified as "primary", developing in the free-field soil, and "secondary", resulting from the oscillating foundation [2]: these were not distinguished in the parametric study.

In this paper a step further is made, as the relative influence of the "primary" and "secondary" nonlinearities is evaluated. A simple 3-degree-of-freedom plane-strain model simulating the soil-foundation-bridge pier-deck system is subjected to the horizontal acceleration time histories computed at the depth of the foundation centroid from preliminary $1 D$ inelastic ground response analyses performed in free-field conditions. The influence of "primary" nonlinearities is assessed by comparing these results with those obtained after applying seismic inputs coming from $1 D$ nonlinear viscous-elastic free-field analyses. The comparison is performed in terms of some performance indexes, such as the deck drift and the bending moment acting at the base of the pier. A fair estimate of the influence of "secondary" nonlinearities is finally provided comparing the results obtained applying the $1 D$ inelastic free-field motion with those computed in the $3 D$ nonlinear dynamic FE analyses.
\end{abstract}

Keywords: Soil Nonlinearities, Caisson Foundation, Bridge Pier, Earthquake, Dynamic SoilStructure Interaction, Finite Element Analysis. 


\section{INTRODUCTION}

Role of soils on the seismic performance of superstructure such as buildings and bridges has been being explored with increasing accuracy for the last 50 years. However, its influence has been often condensed in the increase of flexibility of the soil-foundation-structure system seen as a whole and of the damping with respect to the fixed-base case, thanks to the introduction of the foundation-soil finite stiffness and of the geometric and material damping $[3,4]$. This change in the dynamic properties is even more pronounced when the system is hit by high-intensity earthquakes, as a result of the decreasing shear modulus and growing damping ratio as a function of the shear strain experienced by the foundation soils during the seismic event. The increase of the period of the equivalent system can be easily evaluated even through analytical relationships, provided that at least a preliminary 1D ground response analysis is performed in free-field conditions via the Linear Equivalent ( $L E)$ method [5], so that the magnitude of the shear strain to be expected is properly evaluated. Although this approach allows the user to account for the nonlinear behaviour of foundation soils, it does not permit any evaluation of the effects of their inelastic behaviour, the latter implying the accumulation of permanent deformations until the end of the seismic shaking. Indeed, this aspect can strongly affect the seismic performance of structures subjected to strong ground motions and should be carefully assessed.

In the above-mentioned context, Gaudio and Rampello [1] recently performed a parametric study through 3D nonlinear dynamic FE analyses on caisson foundations of bridge piers subjected to strong ground motions, clearly showing that the influence of soil inelastic behaviour is to be considered when assessing their seismic performance, especially when the fundamental period of the whole soil-caisson-pier-deck system (i.e. considering lengthening of the period due to soil-structure interaction), $T_{\mathrm{eq}}$, approaches the period of the free-field 1D soil column, $T_{0}$. They also discussed the influence of Foundation Input Motion (FIM) and compared it with that of irreversible soil behaviour. Although the study [1] provides some useful empirical relationships that can be used to get the overestimation of peak displacements and forces that is typically obtained when irreversible and hysteretic soil behaviour is neglected, as a function of the period ratio $T_{\mathrm{eq}} / T_{0}$ and of the significant duration of the earthquake, $T_{\mathrm{D}}{ }^{\text {inp }}$ [6], it does not detail the contribution of the so-called "primary" and "secondary" soil nonlinearities (even if "nonlinearities" should be replaced with "plasticity" in this context, more properly). The term "primary" stands for the development of permanent deformations and dissipation of energy in the free-field soil column, whereas "secondary" indicates the same but caused by the oscillating foundation and by the structure as a whole.

In this paper, the relative influence of the primary and secondary nonlinearities is evaluated, following the work that can be found in [1]. Specifically, a 3-degree-of-freedom (3DoF) plane-strain model representing several soil-foundation-bridge pier-deck systems is subjected to the horizontal acceleration time histories computed at the depth of the foundation centroid from preliminary 1D inelastic free-field ground response analyses. The influence of "primary" nonlinearities is first assessed by comparing these results with those computed applying at the node representing the foundation the input motions retrieved from 1D nonlinear viscouselastic free-field analyses. The comparison is performed in terms of the deck drift and the bending moment acting at the base of the pier. A fair estimate of the influence of "secondary" nonlinearities is then provided through the comparison of the results obtained applying the 1D inelastic free-field motion with those computed in the 3D nonlinear dynamic FE analyses in which the soil-foundation-pier-deck system is described. Although not rigorous, this procedure permits clearly understanding, for the cases at hand, of the relative contribution of soil far and close to the structure. 


\section{PROBLEM SETTING}

The problem layout considered in the parametric study is depicted in Figure 1a. The transversal section of a bridge is considered, where the cylindrical caisson foundation of height $H$ and diameter $D$ is embedded in a 5-m-thick gravelly sand layer underlain by a 55-m-thick layer of silty clay, this being representative of an alluvial deposit. The infinitely-rigid bedrock is located at depth $Z=60 \mathrm{~m}$, where the seismic input motion is applied in the $x$ direction in terms of horizontal acceleration time histories. Water table is placed at the interface between the sand and the clay layers $\left(z_{\mathrm{w}}=5 \mathrm{~m}\right)$, with a hydrostatic pore water pressure regime. The pier is modelled through a linear viscous-elastic Single-Degree-of-Freedom System (SDoF) characterized by a stiffness $k_{\mathrm{s}}$, simulating the flexural stiffness of the pier, a damping ratio $\xi_{\mathrm{s}}=5 \%$ and a lumped mass $m_{\mathrm{s}}=m_{\text {deck }}+0.5 \cdot m_{\text {pier }}$, where $m_{\text {deck }}$ and $0.5 \cdot m_{\text {pier }}$ are the mass of the deck and of the upper half of the pier, respectively. The mass of the lower half of the pier is applied to the top of the caisson via a uniform distribution of vertical stresses $\sigma_{\mathrm{z}(0.5 \mathrm{pier}) \text {. }}$

Mechanical properties of the foundation soils are given in Table 1, where $\gamma$ is the unit weight, $c^{\prime}$ and $\varphi^{\prime}$ are the effective cohesion and the angle of shearing resistance, $O C R$ is the overconsolidation ratio and $k_{0}$ is the earth pressure coefficient at rest [7]. The profile assumed for the small-strain shear modulus $G_{0}$ was obtained using the empirical relations proposed by Hardin and Richart [8] for the gravelly sand and by Rampello et al. [9] for the silty clay, and

\begin{tabular}{lcccccccccccc}
\hline Soil & $\begin{array}{c}\gamma \\
\left(\mathrm{kN} / \mathrm{m}^{3}\right)\end{array}$ & $\begin{array}{c}c^{\prime} \\
(\mathrm{kPa})\end{array}$ & $\begin{array}{c}\varphi^{\prime} \\
\left({ }^{\circ}\right)\end{array}$ & $\begin{array}{c}O C R \\
(-)\end{array}$ & $\begin{array}{c}k_{0} \\
(-)\end{array}$ & $\begin{array}{c}G_{0}{ }^{\mathrm{rel}} \\
(\mathrm{MPa})\end{array}$ & $\begin{array}{c}m \\
(-)\end{array}$ & $\begin{array}{c}\gamma_{0.7} \\
(\%)\end{array}$ & $\begin{array}{c}E_{\mathrm{ur}}{ }^{\mathrm{rel}} \\
(\mathrm{MPa})\end{array}$ & $\begin{array}{c}v_{\mathrm{ur}} \\
(-)\end{array}$ & $\begin{array}{c}E_{50}{ }^{\mathrm{rer}} \\
(\mathrm{MPa})\end{array}$ & $\begin{array}{c}E_{\text {oed }}{ }^{\mathrm{rer}} \\
(\mathrm{MPa})\end{array}$ \\
\hline Gravelly sand & 20 & 0 & 30 & 1.0 & 0.5 & 145.7 & 0.61 & 0.024 & 174.9 & 0.2 & 58.3 & 58.3 \\
Silty clay & 20 & 20 & 23 & $4.4 \div 1.5$ & $1.1 \div 0.7$ & 65.7 & 0.75 & 0.045 & 58.2 & 0.2 & 19.4 & 19.4 \\
\hline
\end{tabular}

Table 1: Mechanical properties assumed for soils and adopted in the HS small model.

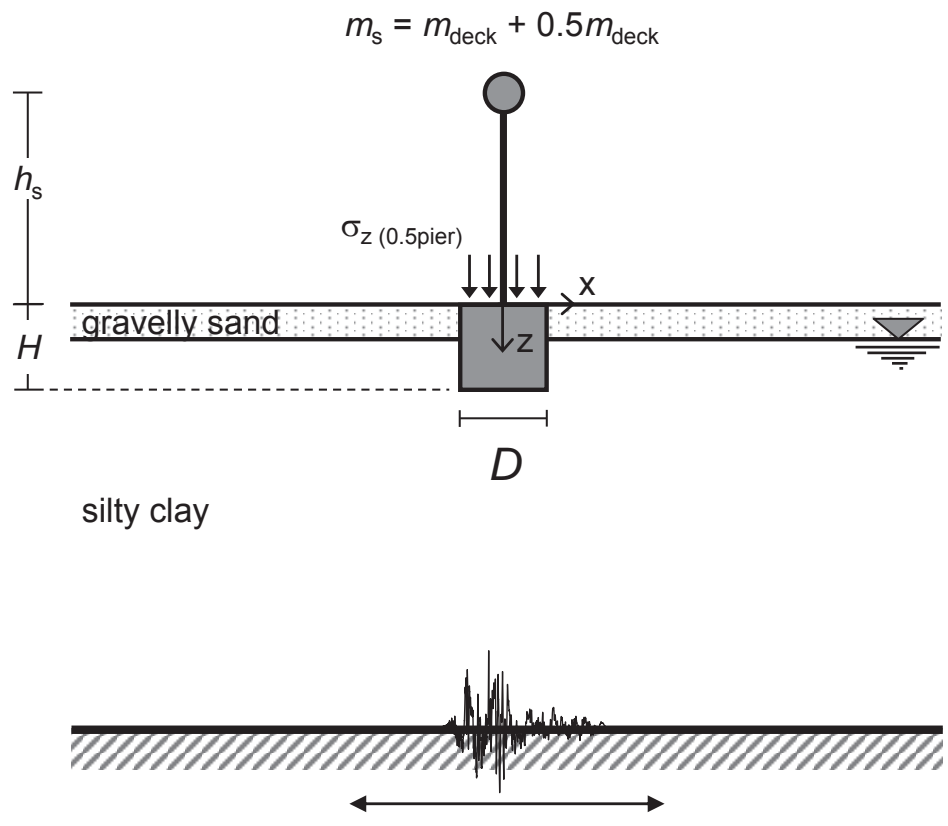

(a)

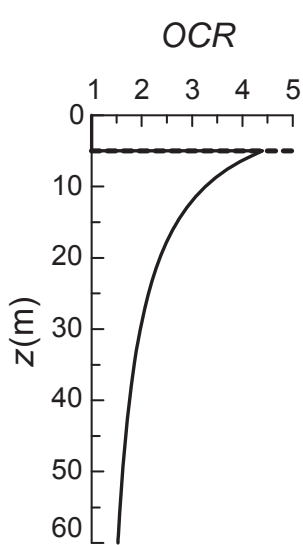

(b)

Figure 1: (a) layout considered in the parametric study; (b) profiles assumed for the overconsolidation ratio and the small-strain shear modulus (modified from [10]). 


\begin{tabular}{|c|c|c|c|c|c|c|}
\hline $\begin{array}{c}D \\
(\mathrm{~m})\end{array}$ & $\begin{array}{c}H / D \\
(-)\end{array}$ & $\begin{array}{l}h_{\mathrm{s}} \\
(\mathrm{m})\end{array}$ & $\begin{array}{c}k_{\mathrm{s}} \\
(\mathrm{MN} / \mathrm{m})\end{array}$ & $\begin{array}{c}m_{\text {deck }} \\
(\mathrm{Mg})\end{array}$ & $\begin{array}{l}m_{\text {pier }} \\
(\mathrm{Mg})\end{array}$ & $\begin{array}{c}m_{\mathrm{s}} \\
(\mathrm{Mg})\end{array}$ \\
\hline \multirow{6}{*}{8} & 0.5 & 15 & 10.1 & 1278.0 & 196.7 & 1376.4 \\
\hline & \multirow{2}{*}{1} & 30 & 11.8 & 1500.3 & 217.2 & 1608.9 \\
\hline & & 60 & 6.2 & 698.6 & 1018.9 & 1208.1 \\
\hline & \multirow{3}{*}{2} & 15 & 102.4 & 2115.4 & 112.0 & 2171.4 \\
\hline & & 30 & 46.9 & 1804.8 & 422.6 & 2016.1 \\
\hline & & 60 & 20.8 & 1162.4 & 1065.0 & 1694.9 \\
\hline \multirow{8}{*}{12} & \multirow{3}{*}{0.5} & 15 & 106.4 & 3445.1 & 113.2 & 3501.7 \\
\hline & & 30 & 37.7 & 3173.5 & 384.8 & 3365.9 \\
\hline & & 60 & 19.8 & 2159.0 & 1399.3 & 2858.6 \\
\hline & \multirow{3}{*}{1} & 15 & 169.3 & 4160.5 & 134.6 & 4227.8 \\
\hline & & 30 & 78.7 & 3806.0 & 489.2 & 4050.6 \\
\hline & & 60 & 29.9 & 2841.1 & 1454.0 & 3568.1 \\
\hline & \multirow{2}{*}{2} & 30 & 411.2 & 4986.9 & 904.2 & 5439.0 \\
\hline & & 60 & 192.3 & 2374.3 & 3156.8 & 4132.7 \\
\hline
\end{tabular}

Table 2: Properties of the systems considered in the parametric study.

is plotted in Figure $1 \mathrm{~b}$ together with that of $O C R$.

In the parametric study fourteen deck-pier-caisson-soil systems were considered, differing in caisson diameter $(D=8$ and $12 \mathrm{~m})$, caisson slenderness ratio $(H / D=0.5,1$ and 2$)$, and pier height $\left(h_{\mathrm{s}}=15,30\right.$ and $\left.60 \mathrm{~m}\right)$. Here it is worth noting that some extreme cases were excluded as they were deemed not realistic (i.e. pier of height $h_{\mathrm{s}}=15 \mathrm{~m}$ over a 24 -m-deep caisson). Values of the pier flexural stiffness $k_{\mathrm{s}}$ and masses $m_{\text {deck }}, m_{\text {pier }}$ and $m_{\mathrm{s}}$ were selected to represent span lengths ranging between 40 and $110 \mathrm{~m}$ and to return fixed values of the safety factor against bearing capacity under static and pseudo-static conditions, $F_{\mathrm{Sv}}=5.5$ and $F_{\mathrm{Se}}=0.7$, respectively. More details about this methodology are given in [11, 12]; the main characteristics of the systems are reported in Table 2.

\section{FINITE ELEMENT MODELLING}

The dynamic analyses were first performed using the FE code PLAXIS 3D [13] with the numerical domain shown in Figure 2a [1]. Each analysis was performed twice, adopting two different constitutive models for foundation soils: the elastic-plastic constitutive model Hardening Soil with Small-Strain Stiffness (HS small, [14]) and a linear viscous-elastic model, the former with the mechanical parameters given in Table 1, the latter with "mobilised" values of shear modulus $G$ and of damping ratio $\xi$ resulting from preliminary 1D free-field analyses carried out with the $L E$ method. Here it is worth mentioning that the same curves reproducing shear modulus decay and damping ratio increase with the shear strain, $G / G_{0}$ and $\xi=\mathrm{f}(\gamma)$, were assumed in the 3D analyses with $H S$ small and in the 1D free-field analyses with the $L E$ method, namely that proposed by Seed and Idriss [15] for the sand and by Vucetic and Dobry [16] for the clay (plasticity index $I_{\mathrm{P}}=25 \%$ ). In the dynamic calculation phase, the systems were subjected to six different acceleration time histories, intense enough to trigger the bearing capacity of the caisson foundations: for the sake of brevity, only three of them are considered in the following (Fig. 3a-b).

Comparison of results permitted to better understand the role of soil plasticity on the seismic performance of the systems at hand. Albeit these analyses were useful in achieving the proposed objective, they did not allow to properly distinguish in between primary and secondary nonlinearities, as summarised in Table 3. Therefore, a simplified plane-strain 3DoF 


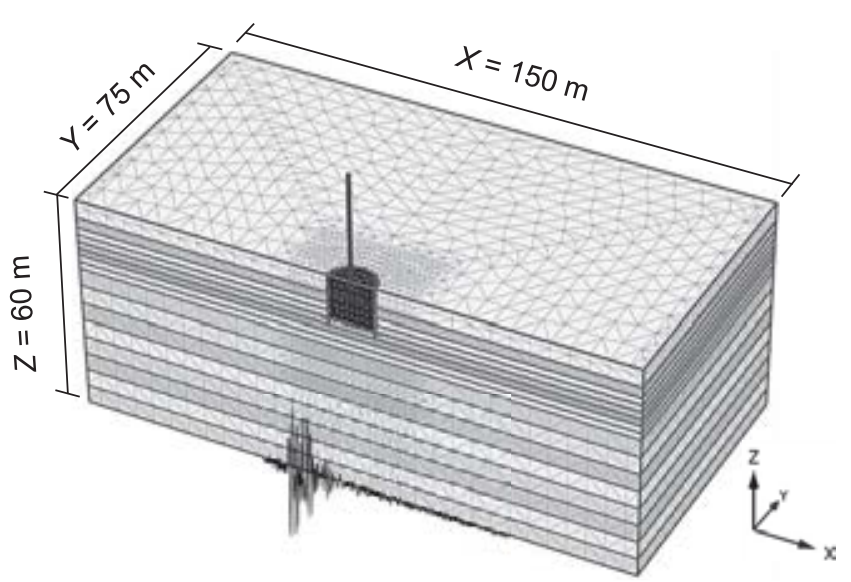

(a)

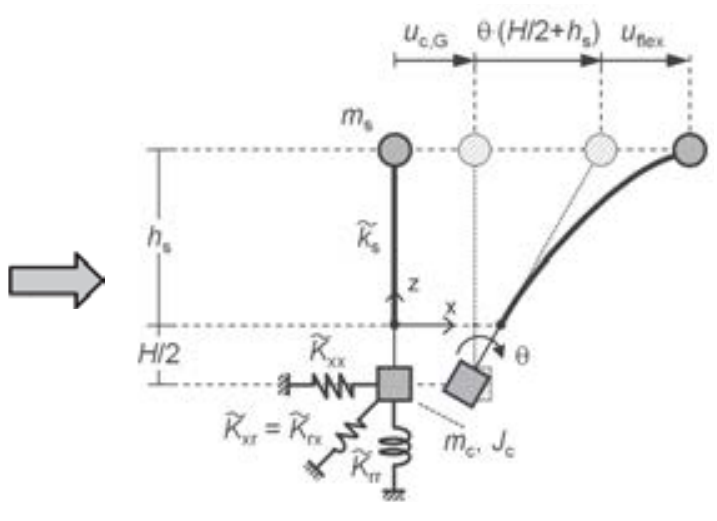

(b)

Figure 2: (a) numerical domain modelled in Plaxis 3D; (b) 3DoF model (modified from [1]).

model was implemented in the FE code SAP2000 v.20 [17], where the three independent degrees of freedom are: the horizontal displacement of the foundation relative to the motion applied to the fixed end of the horizontal impedance $\tilde{K}_{\mathrm{xx}}, u_{\mathrm{c}, \mathrm{G}}$, the angle of caisson rigid rotation $\theta$ and the flexural displacement of the pier column, $u_{\text {flex }}$ (Fig. 2b). This model turned out to be reliable in reproducing the results obtained in the $3 \mathrm{D} \mathrm{FE}$ linear viscous-elastic analyses, provided that the FIM is applied, that the dynamic impedance matrix is computed referring to the "mobilised" values of $G$ and $\xi$ and that the coupled terms $\tilde{K}_{\mathrm{xr}}=\tilde{K}_{\mathrm{rx}}$ are considered [1]. This $3 D o F$ model was also adopted to understand the relative influence of the "primary" and "secondary" soil nonlinearities. To this end, the free-field motion (FFM) computed at the depth of the caisson centroid, $z=z_{\mathrm{G}}$, from preliminary $1 \mathrm{D}$ ground response analyses was applied at the fixed end of the pure-translational dynamic impedance, $\tilde{K}_{\mathrm{xx}}$ : following what already done for the 3D FE analyses, these free-field analyses were performed twice, once adopting HS small and once through the $L E$ method, already implemented in the code MARTA [18] (Tab. 3). Albeit not being rigorous, this procedure permitted to catch the role of primary nonlinearities on the seismic performance of bridge piers over caisson foundations, as it will be clarified in the following section.

\section{1D FREE-FIELD GROUND RESPONSE ANALYSES}

The input motions applied at the base of the $3 D o F$ model were preliminary computed at

\begin{tabular}{|c|c|c|c|c|}
\hline$\#$ & model & soil const. model & seismic input & nonlinearities \\
\hline 1 & $3 \mathrm{D}$ & elastic-plastic & bedrock at at $z=Z$ & $\begin{array}{l}G / G_{0} \text { and } \xi=\mathrm{f}(\gamma), \\
\text { primary, secondary }\end{array}$ \\
\hline 2 & $3 \mathrm{D}$ & linear viscous-elastic & bedrock at $z=Z$ & $G / G_{0}$ and $\xi=\mathrm{f}(\gamma)$ \\
\hline 3 & $3 D o F$ & $\begin{array}{l}\text { nonlinear viscous- } \\
\text { elastic }\end{array}$ & $\begin{array}{l}\text { from 1D free-field analyses with } H S \\
\text { small at } z=z_{\mathrm{G}}\end{array}$ & $\begin{array}{c}G / G_{0} \text { and } \xi=\mathrm{f}(\gamma), \\
\text { primary }\end{array}$ \\
\hline 4 & $3 D o F$ & $\begin{array}{l}\text { nonlinear viscous- } \\
\text { elastic }\end{array}$ & $\begin{array}{l}\text { from } 1 \mathrm{D} \text { free-field analyses with non- } \\
\text { linear viscous-elastic model at } z=z_{\mathrm{G}}\end{array}$ & $G / G_{0}$ and $\xi=\mathrm{f}(\gamma)$ \\
\hline
\end{tabular}

Table 3: FE analyses carried out to assess the influence of the nonlinear and irreversible soil behaviour. 


\begin{tabular}{lccccc}
\hline Record & $\begin{array}{c}F \\
(-)\end{array}$ & $\begin{array}{c}a_{\max }{ }^{\text {Inp }} \\
(\mathrm{g})\end{array}$ & $\begin{array}{c}I_{\mathrm{A}}{ }^{\text {Inp }} \\
(\mathrm{m} / \mathrm{s})\end{array}$ & $\begin{array}{c}T_{\mathrm{m}}{ }^{\text {Inp }} \\
(\mathrm{s})\end{array}$ & $\begin{array}{c}T_{\mathrm{D}}{ }^{\text {Inp }} \\
(\mathrm{s})\end{array}$ \\
\hline Tolmezzo E-W & 1.00 & 0.316 & 1.17 & 0.50 & 5.220 \\
Assisi E-W & 2.00 & 0.332 & 1.12 & 0.24 & 4.295 \\
Adana E-W & 1.05 & 0.292 & 1.17 & 0.62 & 12.990 \\
\hline
\end{tabular}

Table 4: Parameters of the scaled seismic input motions.

the depth $z=z_{\mathrm{G}}=H / 2$ of the caissons' centroid by performing the above-mentioned 1D ground response analyses in free-field conditions twice, once with the elastic-plastic HS small and once with the nonlinear viscous-elastic soil constitutive models. The analyses were carried out imposing at the base of the soil column $(z=Z=60 \mathrm{~m})$ six different high-intensity seismic inputs: for the sake of brevity, only three of them are considered in this paper, whose horizontal acceleration time histories and elastic acceleration spectra are plotted in Figure $3 \mathrm{a}$ and $b$, respectively. The main characteristics of these seismic inputs are listed in Table 4, where $F$ is the amplification factor adopted to reach the desired level of Arias intensity, $a_{\max }$ inp is the peak horizontal acceleration, $I_{\mathrm{A}}{ }^{\text {inp }}$ is the Arias intensity [19], $T_{\mathrm{m}}{ }^{\text {inp }}$ is the mean period [20] and $T_{\mathrm{D}}{ }^{\text {inp }}$ is the strong-motion duration. All the records are characterised by about the same $I_{\mathrm{A}}{ }^{\text {inp: }}$ : moreover, the Assisi record (second line) differs from the Tolmezzo one (first line) in its frequency content $\left(T_{\mathrm{m}}{ }^{\text {inp }}\right)$, having the same strong-motion duration, while the Adana record (third line) differs from Tolmezzo in $T_{\mathrm{D}}{ }^{\text {inp }}$, having about the same frequency content.

The average spectrum resulting from all six records is also plotted in Figure $3 \mathrm{~b}$ for a damping ratio $\xi=5 \%$ (equal to that of the bridge pier, $\xi_{\mathrm{s}}$ ), together with the one resulting from the Italian Building Code [21] for a return period $T_{\mathrm{R}}=1424$ years, taken as a reference to check spectrum compatibility in the entire parametric study.

The inputs applied at the base of the $3 D o F$ models were extracted from the 1D soil column at the depth of the caissons' centroid, as represented in Figure 3c, where the soil column modelled in Plaxis 3D for the elastic-plastic analyses (HS small) is given. The results of the freefield ground response analyses are discussed in the following section.
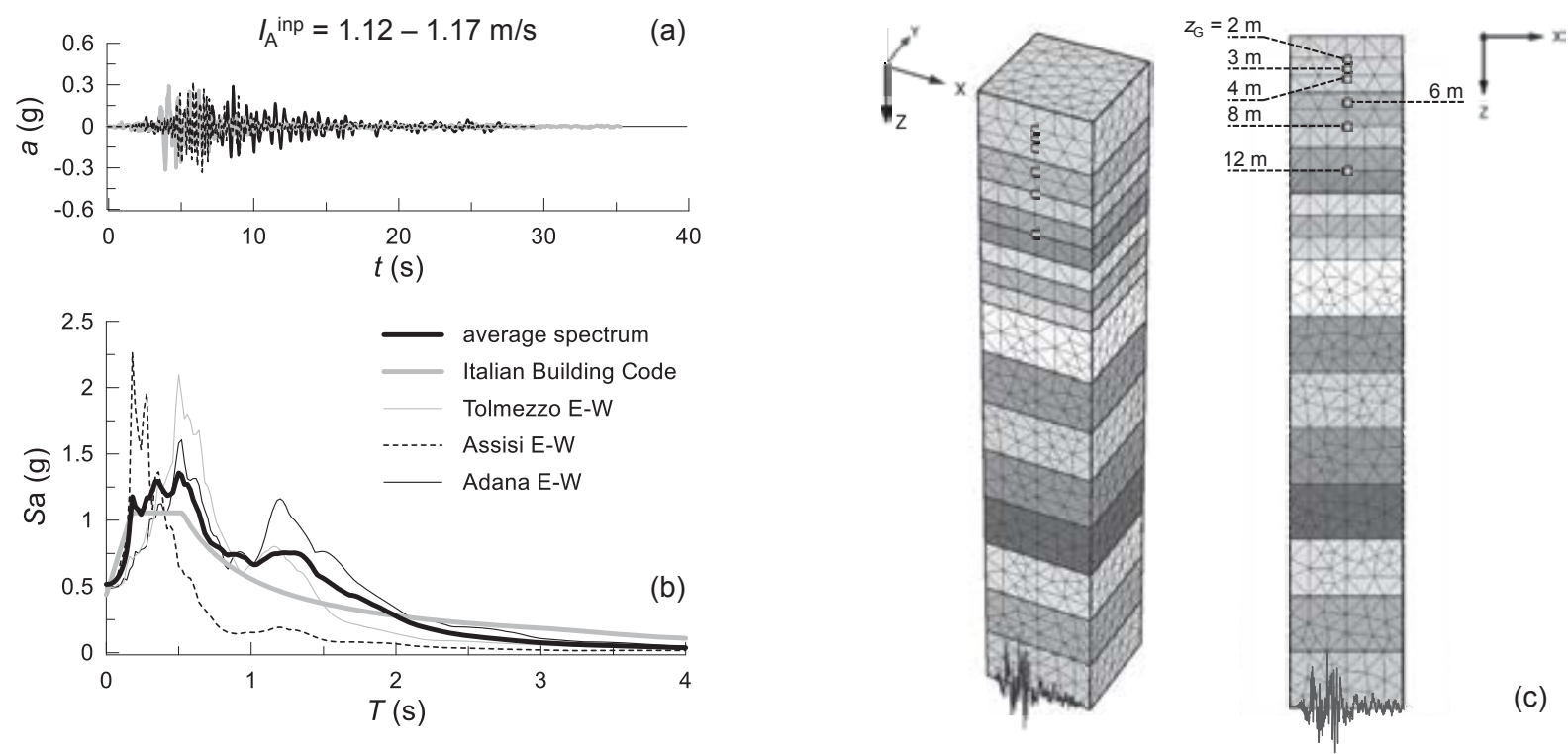

Figure 3: (a) Time histories and (b) elastic spectra of horizontal acceleration of the adopted input motions; (c) soil column modelled in Plaxis for the 1D ground response analysis with HS small and depths at which seismic outputs were extracted. 


\section{INFLUENCE OF PRIMARY SOIL NONLINEARITIES ON THE SEISMIC PERFORMANCE}

The influence of primary soil nonlinearities was assessed by comparing the seismic performance obtained applying to the $3 D o F$ model the horizontal acceleration time histories computed at $z=z_{\mathrm{G}}=H / 2$ in the elastic-plastic and the nonlinear viscous-elastic free-field analyses. Hence, a comparison of free-field results only is first made ( $§ 5.1)$; then, the seismic performance obtained with the $3 D o F$ model is assessed $(\S 5.2)$.

\subsection{Comparison of results in free-field conditions}

A sample of results obtained for the soil column is given in Figure 4 referring to the Tolmezzo record, where profiles of the peak horizontal acceleration (a) and shear strain (b) are plotted, together with the contours of the plastic deviatoric strain $\varepsilon_{\mathrm{s}}^{\mathrm{p}}$ obtained at the end of the earthquake when adopting the HS small constitutive model (elastic-plastic analyses, (c)). The deviatoric strain is the second invariant of the strain tensor, defined as follows:

$$
\varepsilon_{\mathrm{s}}=\sqrt{\frac{2}{3}\left[\left(\varepsilon_{\mathrm{xx}}-\frac{\varepsilon_{\mathrm{v}}}{3}\right)^{2}+\left(\varepsilon_{\mathrm{yy}}-\frac{\varepsilon_{\mathrm{v}}}{3}\right)^{2}+\left(\varepsilon_{\mathrm{zz}}-\frac{\varepsilon_{\mathrm{v}}}{3}\right)^{2}+\frac{1}{2}\left(\gamma_{\mathrm{xy}}^{2}+\gamma_{\mathrm{yz}}^{2}+\gamma_{\mathrm{zx}}^{2}\right)\right]}
$$

where $\varepsilon_{\mathrm{ii}}$ and $\gamma_{\mathrm{ij}}$, for $i \neq j$ and $i, j=x, y, z$ are the components of the strain tensor along the three cartesian directions and $\varepsilon_{\mathrm{v}}=\varepsilon_{\mathrm{xx}}+\varepsilon_{\mathrm{yy}}+\varepsilon_{\mathrm{zz}}$ is the volumetric strain.

The profile of peak horizontal acceleration (Fig. 4a) clearly shows almost overlapping elastic and elastic-plastic profiles from the base of the soil column $(z=Z=60 \mathrm{~m})$ up to a depth $z \approx 17.5 \mathrm{~m}$ : in this range of depths both constitutive assumptions predict a slight reduction of the peak acceleration with respect to the input one $\left(a_{\max }\right.$ inp $\left.=0.316 \mathrm{~g}\right)$. This result is consistent with what observed for the peak shear strain $\gamma_{\max }$ : indeed, similar trends are computed, with slightly higher $\gamma_{\max }$ computed when adopting the nonlinear viscous-elastic soil model. Both analyses provide the same maximum peak shear strain $\gamma_{\max } \approx 0.3 \%$ at depth $z \approx 17.5 \mathrm{~m}$, above
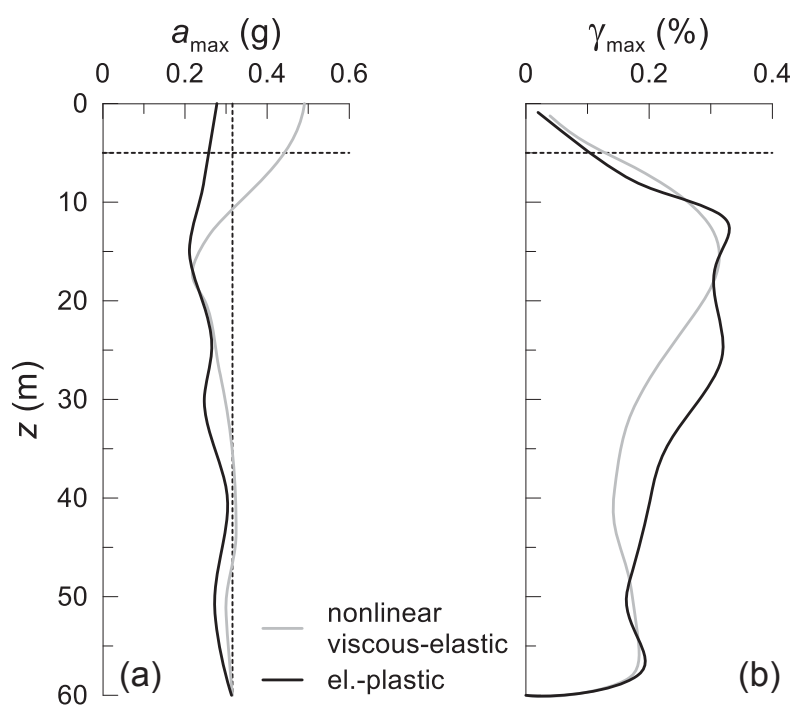

$$
\varepsilon_{\mathrm{s}}^{\mathrm{p}}(\%)
$$

(c)

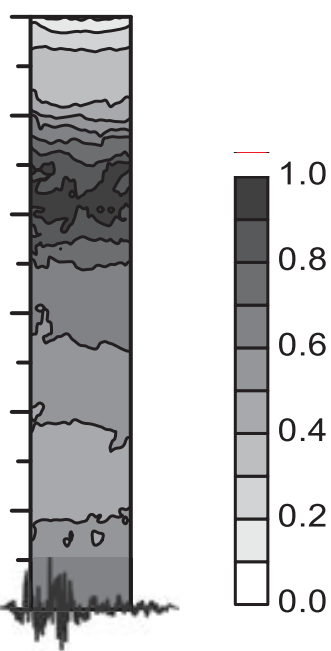

Figure 4: Comparison of 1D free-field ground response analyses when applying the Tolmezzo record: (a) peak acceleration; (b) peak shear strain; (c) contours of the plastic deviatoric strain at the end of the seismic shaking. 

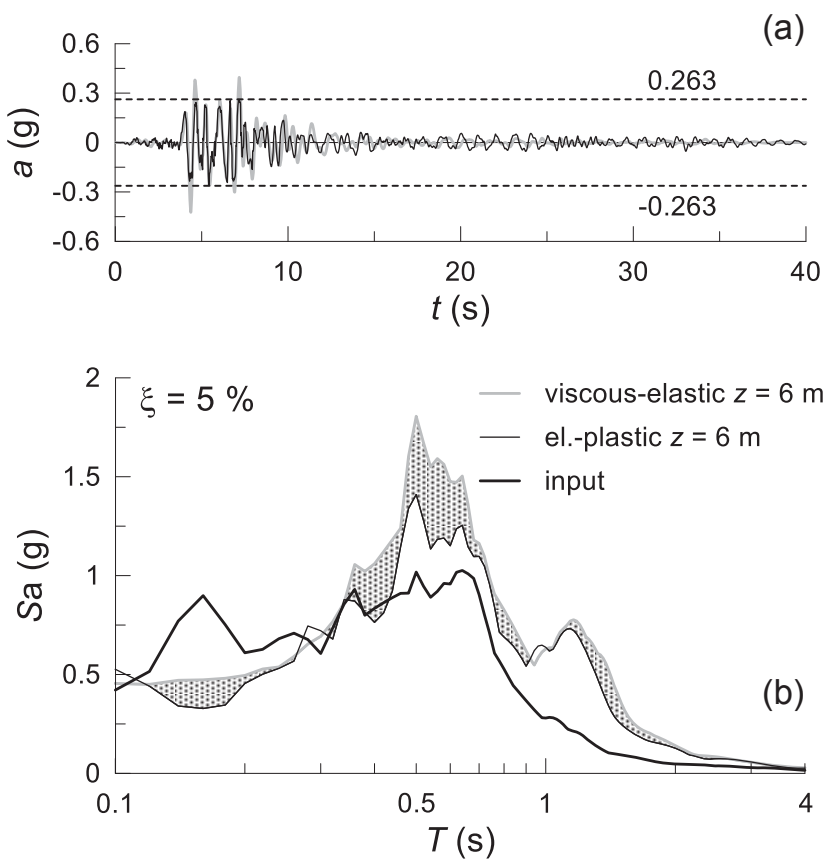

\begin{tabular}{lll}
\hline soil model & $\begin{array}{l}a_{\max } \\
(\mathrm{g})\end{array}$ & $\begin{array}{l}S \mathrm{a}(T=0.5 \mathrm{~s}) \\
(\mathrm{g})\end{array}$ \\
\hline viscous-elastic & 0.423 & 1.806 \\
elastic-pl. & 0.263 & 1.410 \\
\hline ratio & 1.61 & 1.28 \\
\hline
\end{tabular}

Table 5: Intensity measures obtained in the

1D free-field ground response analyses at $z=6 \mathrm{~m}$, for the Tolmezzo record

Figure 5: a) Time histories and (b) elastic spectra of horizontal accelerations computed at depth $z=6 \mathrm{~m}$ in the viscous-elastic and elastic-plastic 1D free-field ground response analyses, together with the Tolmezzo record applied at the base of the column.

which shear strains still go overlapping with the two models. Due to this high distress experienced by the soil, peak horizontal accelerations $a_{\max }$ start diverging when approaching the ground surface, with an almost constant peak acceleration in the elastic-plastic analyses $\left(a_{\max } \approx 0.28 g\right.$ at $\left.z=0\right)$ whereas a strong amplification of motion is predicted by the elastic analysis $\left(a_{\max } \approx 0.50 \mathrm{~g}\right.$ at $\left.z=0\right)$. This result may be attributed to the nonlinear and irreversible behaviour of foundation soils, mostly triggered at $z \approx 20 \mathrm{~m}$, where dissipation of energy occurs, as it is clearly shown by the contours of plastic deviatoric strain $\varepsilon_{\mathrm{s}}{ }^{\mathrm{p}}$ plotted in Figure $4 \mathrm{c}$, that attains its maximum value of about $1 \%$ at the end of the seismic shaking.

The influence of soil dissipating energy introduced by the seismic record on the free-field motion is shown is Figure 5 as well, where the horizontal acceleration time histories (a) and elastic acceleration spectra (b) computed at depth $z=6 \mathrm{~m}$ are plotted for the Tolmezzo record. These results are the input motions applied at the node representing the foundation in the $3 D o F$ model when caisson foundations with $D=12 \mathrm{~m}$ and $H / D=1$ (i.e. $z_{\mathrm{G}}=6 \mathrm{~m}$ ) are considered. The decrease of horizontal accelerations can be recognised in Figure 5a, where the time history computed with $H S$ small shows a cut-off at $a_{\max }=0.263 \mathrm{~g}$, while that obtained with the linear viscous-elastic model attain its peak value $a_{\max }=0.423 \mathrm{~g}$.

Energy dissipation caused by irreversible soil behaviour turned out to be mainly located around the eigenperiods of the free-field soil column, provided that they are effectively activated by the frequency content of the seismic input. Shaded area plotted in Figure $5 \mathrm{~b}$ indicates the range of periods where elastic acceleration spectrum obtained with the nonlinear viscouselastic constitutive model is higher than the elastic-plastic one, this pointing out where dissipation of energy occurs. Main reduction of amplitude is located at $T=0.5 \mathrm{~s}$, this being the second eigenperiod of the soil column; less-intense reduction is observed close to $T=T_{0} \approx 1.0 \mathrm{~s}$, that is the fundamental period of the soil column.

A summary of the obtained values of $a_{\max }$ and $S \mathrm{a}(T=0.5 \mathrm{~s})$ is given in Table 5 . 


\subsection{Seismic performance of the system}

The influence of primary nonlinearities on the seismic performance of the whole system was evaluated through the comparison of results obtained applying at the base of the $3 D o F$ model the free-field motions computed with the HS small and the nonlinear viscous-elastic soil models (Fig. 2b). With the three above-mentioned records (Tab. 4) and the fourteen systems considered in the parametric study (Tab. 2), 42 linear dynamic analyses were performed twice in the time domain, this returning a total amount of 84 analyses. A comparison of results is given in Figure 6, where the time histories of deck drift $u_{\text {rel }}$ and bending moment acting at the pier base $M_{\mathrm{s}}$ are plotted, for the system with $D=12 \mathrm{~m}, H / D=1$ and $h_{\mathrm{s}}=15 \mathrm{~m}$, subjected to the free-field motions shown in Figure 5a. As it could have been anticipated from the free-field results, peak values $u_{\text {rel, max }}$ and $M_{\mathrm{s} \text {, max }}$, here assumed as seismic performance indexes, attain lower values when considering elastic-plastic soil behaviour. Specifically, an overestimation of about $20 \%$ is computed when ignoring soil plasticity, as summarised in Table 6 , whereas a quite similar frequency content is obtained for both time histories. Therefore, primary nonlinearities do affect the seismic performance of the system. This contribution is compared to secondary nonlinearities in the following section.

\section{INFLUENCE OF SECONDARY SOIL NONLINEARITIES ON THE SEISMIC PERFORMANCE}

The influence of secondary soil nonlinearities was finally assessed comparing the seismic performance indexes $u_{\text {rel, max }}$ and $M_{\mathrm{s} \text {, max }}$ obtained in the proper 3D elastic-plastic analyses of the whole system carried out through the Plaxis numerical model (Fig. 2a and first line of Tab. 3) with the relevant results computed through the $3 D o F$ model when applying the elastic-plastic (i.e. HS small, third line of Tab. 3) 1D free-field motion. Figure 7 shows that the vast majority of results lay above the 1:1 line for both the deck drift (a) and the bending moment at the pier base (b), this indicating that soil irreversible strains developing close to the oscillating foundation during the seismic event play a remarkable role in improving the seis-
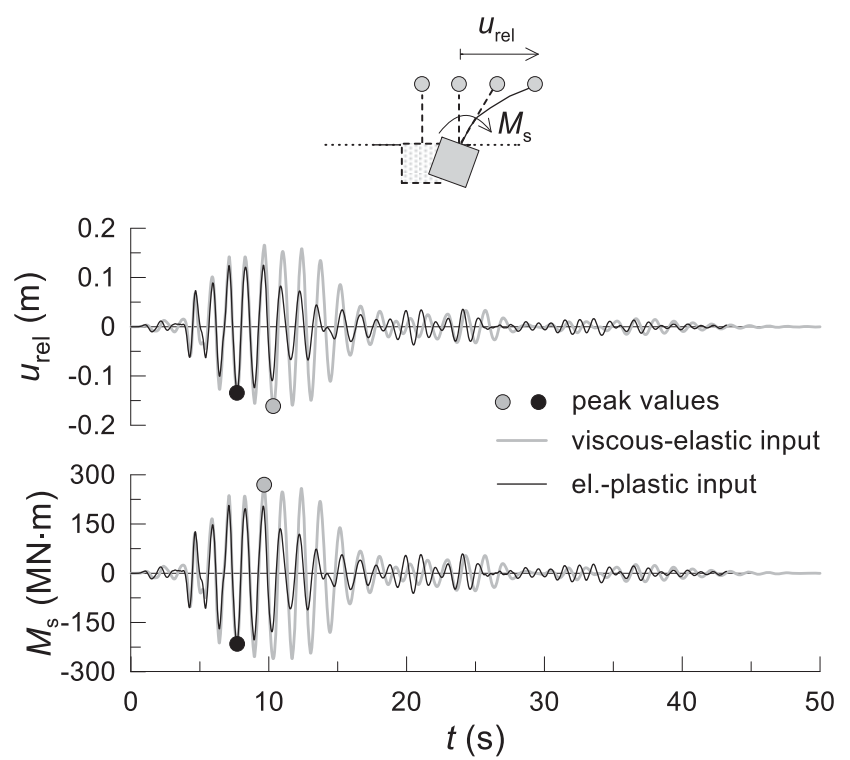

\begin{tabular}{lll}
\hline input from & $\begin{array}{l}u_{\text {rel, } \max } \\
(\mathrm{m})\end{array}$ & $\begin{array}{l}M_{\mathrm{s}, \max } \\
(\mathrm{MN} \cdot \mathrm{m})\end{array}$ \\
\hline viscous-elastic 1D & 0.166 & 267.49 \\
elastic-pl. 1D & 0.134 & 220.40 \\
\hline ratio & 1.24 & 1.21 \\
\hline
\end{tabular}

Table 6: Seismic performance indexes computed for the system with $D=12 \mathrm{~m}$, $H / D=1$ and $h_{\mathrm{s}}=15 \mathrm{~m}$, Tolmezzo record

Figure 6: Time histories of (a) deck drift and (b) bending moment computed for the system with $D=12 \mathrm{~m}$, $H / D=1$ and $h_{\mathrm{s}}=15 \mathrm{~m}$ through the $3 \mathrm{DoF}$ model by applying at $z_{\mathrm{G}}$ the acceleration time histories computed with the viscous-elastic and elastic-plastic 1D free-field ground response analyses. 


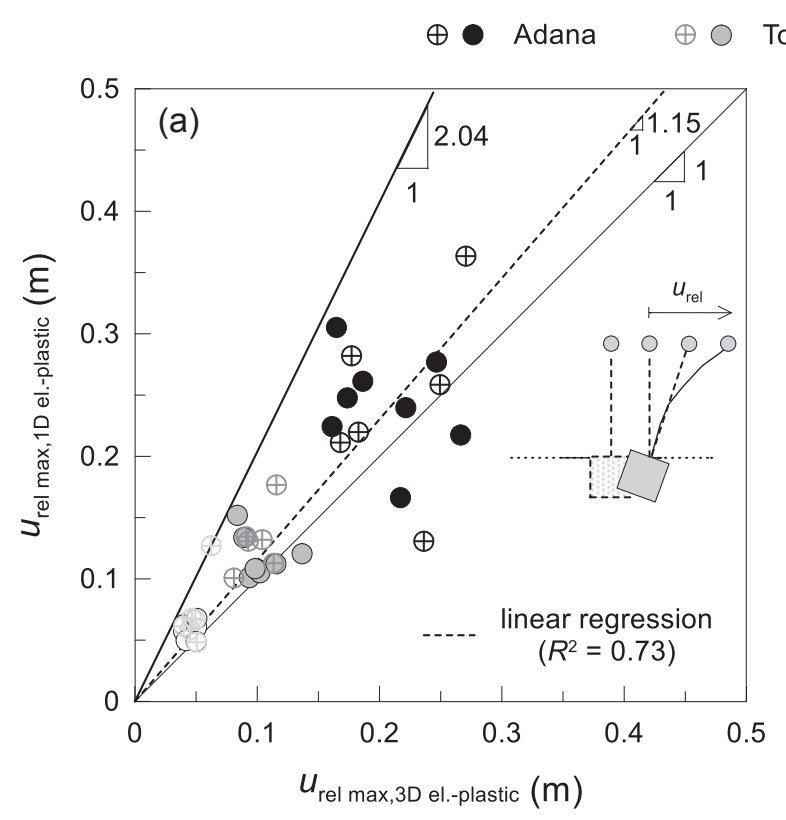

Tolmezzo

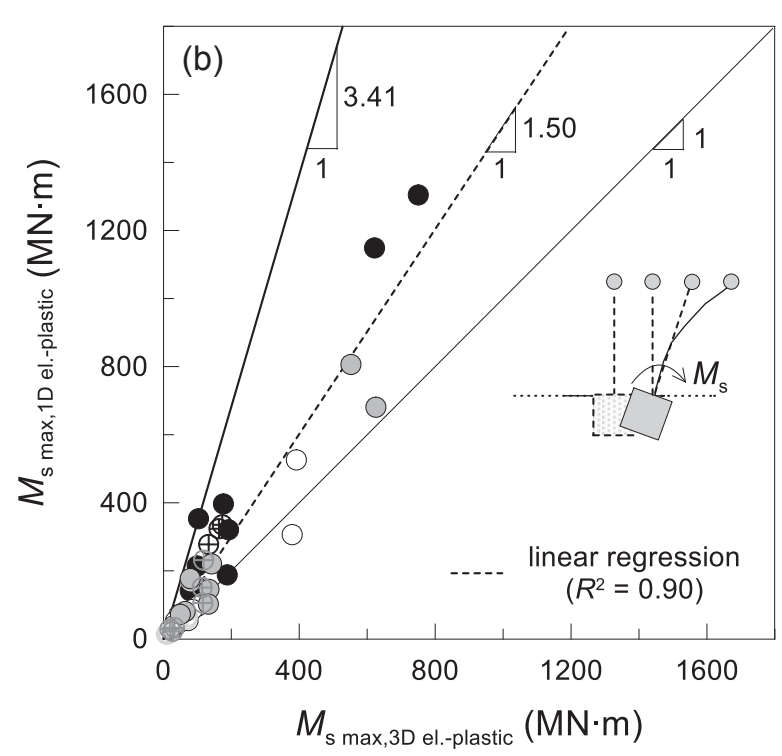

Figure 7: Comparison of results of the 3D elastic-plastic analyses of the whole system with those computed with the 3DoF model applying as input motion the 1D elastic-plastic free-field motion: peak values of (a) deck drift and (b) bending moment.

mic performance of the systems at hand, together with some kinematic interaction effects. In order to quantify the average overestimation of the peak values $u_{\mathrm{rel}, \max }$ and $M_{\mathrm{s} \text {, max }}$ when performing the analyses with the $3 D o F$ model subjected to the 1D elastic-plastic free-field motion, the slope of a standard linear regression was computed. Values equal to 1.15 and 1.50 were obtained for the deck drift and the bending moment, respectively, while a maximum overestimation of about 2.0 and 3.4 times was obtained, this clearly showing that the influence of secondary soil nonlinearities is stronger in reducing the inertial forces transmitted to the superstructure than the displacements. The role of the applied seismic inputs and of the caisson diameter on the contribution of secondary nonlinearities is not clear enough to draw any conclusion.

Graphs similar to those commented above are given in Figure 8, where the seismic performance computed in the 3D elastic-plastic analyses of the whole system is compared with the one obtained applying the nonlinear viscous-elastic 1D free-field motion to the base of the $3 D o F$ model. As expected, higher slopes are obtained in Figure 8, as now the results include both the effects of primary and secondary nonlinearities: specifically, slopes equal to 1.25 and 1.63 were obtained for $u_{\mathrm{rel}, \max }$ and $M_{\mathrm{s} \text {, max }}$, with a maximum overestimation of about 2.73 and 3.87, respectively. The ratio between the slopes of linear regressions shown in Figures 7 and 8 allows to get a quick estimate of the relative influence of the primary and secondary soil nonlinearities: with reference to the average overestimation, about the same ratio is obtained for the deck drift and the bending moment, equal to about $9 \%(1.25 / 1.15 \approx 1.63 / 1.50 \approx 1.09)$. This result suggests that, on average, neglecting primary nonlinearities would imply overestimating the peak values of the deck drift and bending moment of about $9 \%$, whereas disregarding secondary nonlinearities would entail overestimating the seismic performance indexes of about 15 and $50 \%$, respectively for $u_{\mathrm{rel}, \max }$ and $M_{\mathrm{s} \text {, max }}$, this proving the bigger role of soil plasticity developed close to the oscillating foundation than the one already triggered in freefield conditions for the cases at hand. 

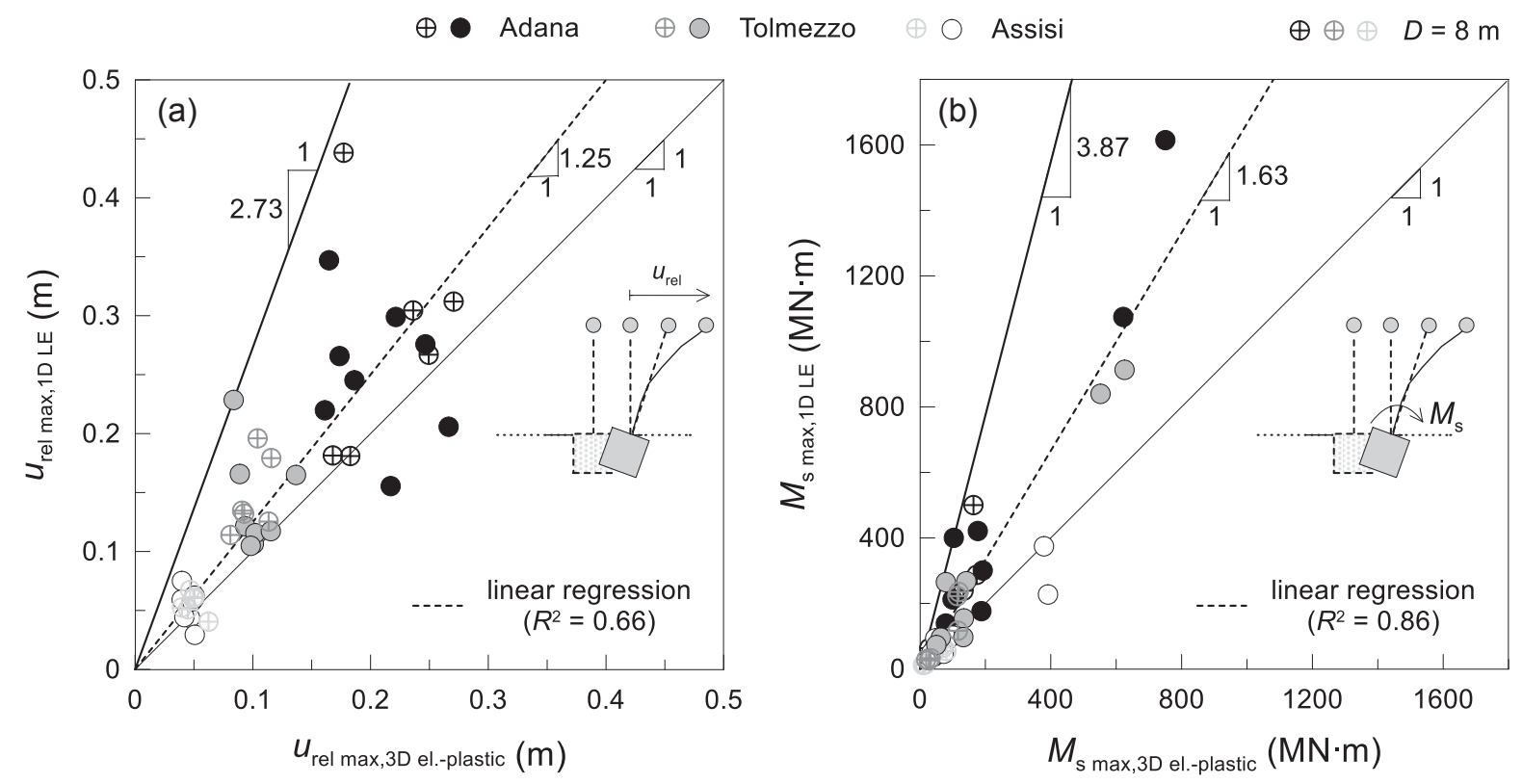

Figure 8: Comparison of results of the 3D elastic-plastic analyses with those computed with the 3DoF model applying as input motion the 1D LE free-field motion: peak values of (a) deck drift and (b) bending moment.

\section{CONCLUSIONS}

In this paper, the influence of irreversible and hysteretic soil behaviour occurring far (primary) and close (secondary) to oscillating caisson foundations supporting bridge piers has been assessed. To this end, free-field motion acting at the depth of the caisson centroids has been evaluated through 1D nonlinear viscous-elastic and elastic-plastic ground response analyses performed applying strong ground motions, capable of activating plastic soil behaviour. Then, the computed acceleration time histories have been applied to the node representing the soil-caisson system in a simple plain-strain 3-degree-of-freedom linear viscous-elastic structural model. The results have been compared with those obtained from a parametric study carried out on the whole soil-caisson-pier-deck system through 3D nonlinear dynamic FE analyses, using the peak deck drift and the bending moment at the base of the pier as performance indexes.

The comparison clearly indicates that, as it could be anticipated, primary soil nonlinearities imply a reduction of both $u_{\mathrm{rel}, \max }$ and $M_{\mathrm{s} \text {, max }}$, but only of about $9 \%$, which might be deemed negligible. Conversely, the role of secondary nonlinearities is more pronounced, as this entailed a reduction approaching 15\% for the deck drift and even $50 \%$ for the bending moment, this clearly indicating the major role of irreversible and hysteretic soil behaviour developing close to the foundation when hit by strong earthquakes.

Two main limitations arise in the study: first, there is the underlying assumption for which the effects of primary and secondary soil nonlinearities can be added. Clearly, this is a strong approximation, as in the inelastic regime the superposition principle does not hold: nonetheless, the discussed results may still shed some light on the relative influence of primary and secondary soil nonlinearities. Second, analyses may need some extension in terms of amount of systems and seismic inputs to be adopted, so as to make the study gain more generality and applicability to cases that have not been directly considered in the analyses, although the discussed results can be deemed suitable to soils whose stiffness linearly increases with depth. However, adopted systems and records already cover a wide range of cases typically encountered in the common practice and are representative of a large variety of input characteristics. 


\section{REFERENCES}

[1] D. Gaudio, S. Rampello, On the assessment of seismic performance of bridge piers on caisson foundations subjected to strong ground motions. Earthquake Engineering and Structural Dynamics, 50 (5), 1429-1450, 2021. DOI: https://doi.org/10.1002/eqe.3407

[2] G. Mylonakis, S. Nikolaou, G. Gazetas, Footings under seismic loading: Analysis and design issues with emphasis on bridge foundations, Soil Dynamics and Earthquake Engineering, 26, 824-853, 2006.

[3] A.S. Veletsos, J.W. Meek, Dynamic behaviour of building-foundation systems, Earthquake Engineering and Structural Dynamics, 3, 121-138, 1974.

[4] J.P. Wolf, Dynamic soil-structure interaction, Prentice-Hall, 1985.

[5] I.M. Idriss, H.M. Seed, Response of horizontal soil layers during earthquakes, Journal of the Soil Mechanics and Foundation Division, ASCE, 94 (SM4) 1003-1031, 1968.

[6] M.D. Trifunac, A.G. Brady, A study on the duration of strong earthquake ground motion. Bulletin of the Seismological Society of America, 65 (3), 581-626, 1975.

[7] P.W. Mayne, F.H. Kulhawy, K0 - OCR relationships in soil. Journal of the Geotechnical Engineering Division, ASCE, 108 (GT6) 851-872, 1982.

[8] B.O. Hardin, F.E. Richart, Elastic wave velocities in granular soils. Journal of the Soil Mechanics and Foundation Division, ASCE, 89 (SM1) 33-65, 1963.

[9] S. Rampello, F. Silvestri, G. Viggiani, The dependence of G0 on stress state and history in cohesive soils. Balkema ed. $I^{\text {st }}$ International Symposium on Pre-Failure Deformation Characteristics of Geomaterials - Measurements and Applications, 2, 1155-1160, Sapporo, Japan, 1994.

[10] D. Gaudio, S. Rampello, Equivalent seismic coefficients for caisson foundations supporting bridge piers. Soil Dynamics and Earthquake Engineering, 129, 105955, 2020. DOI: https://doi.org/10.1016/j.soildyn.2019.105955

[11] D. Gaudio, S. Rampello, The influence of soil plasticity on the seismic performance of bridge piers on caisson foundations. Soil Dynamics and Earthquake Engineering, 118, 120-133, 2019. DOI: https://doi.org/10.1016/j.soildyn.2018.12.007

[12] D. Gaudio, S. Rampello, The role of soil constitutive modelling on the assessment of seismic performance of caisson foundations. Silvestri \& Moraci eds. $7^{\text {th }}$ International Conference on Geotechnical Earthquake Engineering, Rome, Italy, June 17-20, 2019, pp. 2574-2582.

[13] R.B.J. Brinkgreve, E. Engine, W.M. Swolfs, PLAXIS 3D. Reference Manual, 2013.

[14] T. Benz, P.A. Vermeer, R. Schwab, A small-strain overlay model. International Journal for Numerical and Analytical Methods in Geomechanics, 33 (1), 25-44, 2009.

[15] H.B. Seed, I.M. Idriss, Soil moduli and damping factors for dynamic response analyses, Report No. EERC 70-10. Earthquake Engineering Research Centre, University of California, Berkeley, California, 1970.

[16] M. Vucetic, R. Dobry, Effect of soil plasticity on cyclic response. Journal of Geotechnical Engineering, 117 (1), 89-107, 1991. 
[17] CSI (Computer and Structures Inc.), SAP2000: integrated finite element analysis and design of structures, 2017.

[18] L. Callisto, MARTA v. 1.1: a computer program for the site response analysis of a layered soil deposit, 2015.

[19] A. Arias, A measure of earthquake intensity. Seismic design for nuclear power plants. Cambridge MA: Massachusetts Institute of Technology Press, Hansen RJ ed., pp. 438483, 1970.

[20] E.M. Rathje, N. Abrahamson, J.D. Bray, Simplified frequency content estimates of earthquake ground motions. Journal of Geotechnical and Geoenvironmental Engineering, ASCE, 124 (2), 150-159, 1998.

[21] Ministero delle Infrastrutture. Norme tecniche per le Costruzioni, Gazzetta Ufficiale della Repubblica Italiana 42, Decreto Ministero Infrastrutture 17.01.2018, Rome (in Italian), 2018. 